\title{
Assessing Population Trend and Risk of Extinction for Cetaceans Lacking Long- Term Census Baselines
}

\author{
Shiang-Lin Huang* \\ Department of Environmental Biology and Fishery Science, National Taiwan Ocean University, Keelung, Taiwan
}

\begin{abstract}
Assessment of population trend and risk of extinction, essential for informed conservation, needs baselines including percentage of population decline, extent of occurrence, population size, population structure and probabilities of extinction. Construction of these baselines usually claims long-term census efforts that are often insufficient or even lacking for many cetaceans, especially for those nearby rapidly developing countries. Restricted to variation from current census techniques, however, the approach based on long-term census database is unlikely to detect early or recent sign of population decline. Here, I propose an integrative perspective, the systematic demographic analysis, to solve life history and demographic parameters essential for status and risk assessment for the cetacean populations. Transect technique with the aid of GPS records and environmental characteristics can be used to estimate population abundance and figure the extent of occurrence and critical habitat, information essential for sound habitat protection. Capturemark-recapture technique based on the database from individual photo-ID histories can be used to estimate population size, apparent survival rate and life history parameters. Collections of stranded and by caught carcasses can be used to solve life history parameters, age-specific survivorships or mortality rates and population genetic diversity indirectly relating to population size. Applications of population viability analysis to above parameters such as VORTEX model or other individual-based stage/age matrix model that factors the stochasticity and uncertainty can be used to solve the likely range of rate of decline and extinction risk of threatened population. Finally, I emphasize the need to integrate the histories of long-term land use and landscape change when formulating habitat management programme for the rare and/or endangered populations to avoid skipping the low-sighting habitat from intense anthropogenic impacts.
\end{abstract}

Keywords: Trend Analysis; Demography; Census; Capture-MarkRecapture Modeling; Environment Change

\section{Introduction}

Ideally, the precautionary principle of conservation calls necessary actions to prevent or mitigate any threat that is possible to endanger the long-term survival of a population, even if the interaction between threats and population survival has not yet been clearly elucidated. In actual, however, conservation awareness and practice still awaits the clear signs of endangeredness of population survival. In many developing countries, the awareness that the population survival is end angered often arises from evidences like once frequently sighted animals become rare [1] or the implementation of immense environment-developing project will change/is changing natural habitat. In this scenario, the conservation measures often fall behind the pace of population decline and often passively mitigate the obvious threats, the 'crisis management' perspective, rather than actively minimize and ameliorate the endangeredness of survival, the 'crisis prevention' perspective. When dealing with conservation of rare or threatened species/populations, policy makers, stakeholders and scientists frequently ask: What is current status of the species/population concerned? How fast is the current population decline? What is the chance the endangered species or population becomes extinct in future? How many years do we still have to reverse population decline? Answers to these questions lead to the assessment of population status and extinction risk. In the IUCN Red List Categories and Criteria Version 3.1 [2], the risk of extinction and hence population status, either NT (Near Threatened), VU (Vulnerable), $E N$ (Endangered) or CR (Critically Endangered), is classified by a set of quantitative baselines, including percentage of population decline, extent of occurrence or occupancy, population size, population (age) structure and probabilities of extinction within a given time (Table 1). To construct these baselines usually claims long-term census efforts [3-6] that are often insufficient or even lacking for many cetaceans, especially for those in rapidly developing countries. The baselines for status and risk assessment of the threatened populations/species can be approached by several techniques in cetaceans, from long-term and periodical census monitoring [7] to meta-analysis of stranded and/or by caught carcass collections $[8,9]$. Careful use of these techniques with sufficient attention on their theoretical assumptions and limitations can facilitate stepping up conservation efforts and moving on from precautionary management to informed conservation strategies. It is my goal to summarize the techniques frequently used to solve the population trend and status/risk assessment in many cetaceans. This summarization could be helpful for the conservation of cetaceans for forming sound conservation actions, especial for the species inhabiting freshwater habitats and coastal waters under intensive anthropogenic threats [10-17] in developing countries.

\section{Long-term census: How long is long enough?}

Theoretically, the population trend can be solved by applying regression modeling to long-term census records $[4-6,18,19]$. In practice, however, the variation from field techniques restricts the resolution of census records to estimate the population trend. There are some studies report population trends by a simple application of statistical methods to historic abundance estimates $[4-6,18,19]$. However, this

*Corresponding author: Dr. Shiang-Lin Huang, Department of Environmental Biology and Fishery Science, National Taiwan Ocean University, Keelung. Taiwan, Tel: 886-920-093-114; E-mail: slhuang@mail.ntou.edu.tw

Received November 20, 2013; Accepted November 26, 2013; Published December 02, 2013

Citation: Huang SL (2013) Assessing Population Trend and Risk of Extinction for Cetaceans Lacking Long-Term Census Baselines. J Biodivers Endanger Species 1: 115. doi: 10.4172/2332-2543.1000115

Copyright: (c) 2013 Huang SL. This is an open-access article distributed under the terms of the Creative Commons Attribution License, which permits unrestricted use, distribution, and reproduction in any medium, provided the original author and source are credited. 
Citation: Huang SL (2013) Assessing Population Trend and Risk of Extinction for Cetaceans Lacking Long-Term Census Baselines. J Biodivers Endanger Species 1: 115. doi: 10.4172/2332-2543.1000115

Page 2 of 8

\begin{tabular}{|c|c|c|c|}
\hline Criteria & baselines & standards & sub-Criteria \\
\hline $\mathrm{A} 2 \mathrm{~b}$ & \multirow{3}{*}{$\%$ decline $(\delta N)$ within three generations ( $0 T$ ) } & \multirow{3}{*}{$\begin{array}{l}N T: 0<\delta N<30 \% \\
V U: 30 \leq \delta N<50 \% \\
E N: 50 \% \leq \delta N<80 \% \\
C R: \delta N \geq 80 \%\end{array}$} & \multirow{3}{*}{$\begin{array}{l}A 2 b: \text { past } \\
A 3 b \text { : future } \\
A 4 b: \text { from past to future }\end{array}$} \\
\hline A3b, & & & \\
\hline$A 4 b$ & & & \\
\hline $\mathrm{B} 1 \mathrm{~b}$ & extent of occurrence & $N T: H>20000 \mathrm{~km} 2$ & b: continuing decline in \\
\hline (iii, v) & $(H)$, declining trend $(r<0)$ & $\begin{array}{l}\text { VU: } 5000 \mathrm{~km} 2<H \leq 20000 \mathrm{~km} 2 \\
E N: 100 \mathrm{~km} 2<H \leq 5000 \mathrm{~km} 2 \\
C R: H \leq 100 \mathrm{~km} 2\end{array}$ & $\begin{array}{l}\text { (iii) area, extent and/or } \\
\text { quality of habitat } \\
\text { (v) number of adults }\end{array}$ \\
\hline $\mathrm{C} 1$ & $\begin{array}{l}\text { 1. number of adults } \\
\text { (female), Ne } \\
\text { 2. \% decline }(\delta N) \\
\text { within one }(C R), \text { two } \\
(E N) \text { or three }(V U) \\
\text { generations }(O T)\end{array}$ & $\begin{array}{l}N T: N e>10000, r<0 \\
V U: 2500<N e 10000 \\
\delta N \geq 10 \% \text { in } 3 T 0 \\
E N: 250<N e \leq 2500 \\
\delta N \geq 20 \% \text { in } 2 T 0 \\
C R: N e \leq 250 \\
\delta N \geq 25 \% \text { in } T 0\end{array}$ & \\
\hline $\mathrm{D}$ & number of adults(female), $\mathrm{Ne}$ & $\begin{array}{l}\text { NT: } \mathrm{Ne}>1000, r<0 \\
\text { VU: } 250<\mathrm{Ne} \leq 1000 \\
\text { EN: } 50<\mathrm{Ne} \leq 250 \\
\text { CR: } \mathrm{Ne} \leq 50\end{array}$ & \\
\hline$E$ & $\begin{array}{l}\text { probabilities of } \\
\text { extinction within } 100 \\
\text { years (PE100), three } \\
\text { generations (PE 3T0) } \\
\text { and five generations } \\
(P E 5 T 0)\end{array}$ & $\begin{array}{l}\text { NT: } P E 100<10 \% \\
\text { VU: } P E 100 \geq 10 \% \text { but } \\
\text { PE } 5 T 0<20 \% \\
\text { EN: } P E 5 T 0 \geq 20 \% \text { but } \\
\text { PE } 3 T 0<50 \% \\
\text { CR: } P E 3 T 0 \geq 50 \%\end{array}$ & \\
\hline
\end{tabular}

Table 1: Standards and population baselines that is suitable for cetaceans to classify NT (Near Threatened), VU (Vulnerable), EN (Endangered) or CR (Critically Endangered) under Criteria A - E of the IUCN Red List Categories and Criteria version 3.1 [2]

exercise should be viewed very cautiously as they may yield statistically "significant" yet actually biased and potentially misguided results [1822]. Such arbitrary conclusions should be of particular concern when the abundance estimates have high variation. [20] Described a power analysis to test if a long-term census database has sufficient "power" to describe a trend. [21] Based on the power analysis indicates that the time needed to detect population change in field (either increase or decrease), $T_{d}$, via annual census frequency is determined by the $\mathrm{CV}$ of census records and average rate of population change $(r)$ :

$$
\mathrm{T}_{\mathrm{d}}=5.38 \times \mathrm{CV}^{2 / 3} \times r^{2 / 3}(1)
$$

[17] Further calculated the Tds needed to detect population decline and classify population status under Criterion A2 of the IUCN Red List Categories and Criteria Version 3.1 [2]. A minimum of a decade of census effort is needed to detect a trend meeting the standard to classify $\mathrm{CR}$ (Figure 1) while a slower rate of decline and hence a classification at lower status (NT, VU or EN) requires longer census history [17]. By the time population decline becomes detectable, a substantial proportion of initial abundance, at least 30\% [17, 21], has been lost (Figure 2).

Thus, even though long-term census history theoretically can be used to reflect population trend, this technique is unlikely to disclose early and/or recent population decline in practice even the census works have been well designed and implemented. Worse, systematic census surveys are seldom implemented across the entire geographic range of a population until the population decline, or anthropogenic impacts, become explicitly apparent, as tragically exemplified by the recent history of the decline and extinction of baiji (Lipotes vexillifer) and Yangtze finless porpoise Yangtze finless porpoise (Neophocaena asiaeorientalis asiaeorientalis) associated research efforts [2325]. In case the population decline associates with the increasing anthropogenic impacts, the delayed response of population decline due to the restriction from variation from census techniques may result in difficulties to restore habitat quality and reverse a decline [17]. For

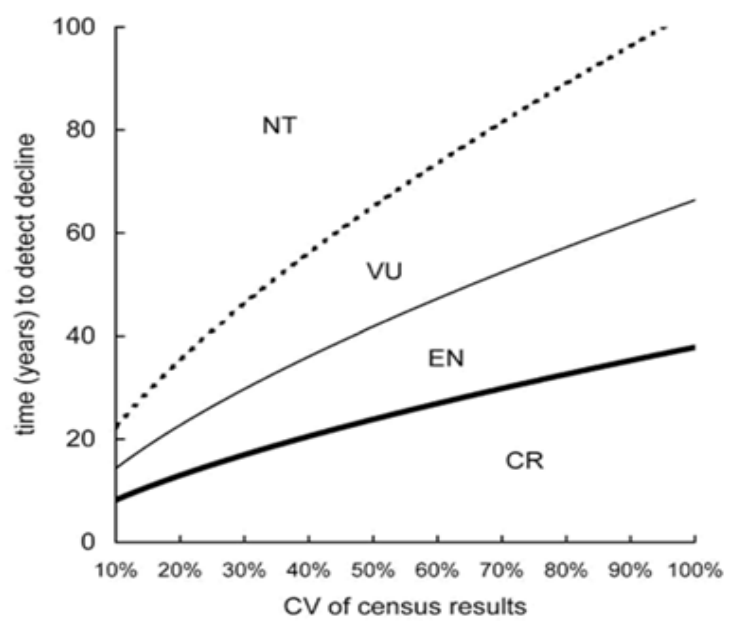

Figure 1: Time needed to detect population decline by periodic census investigation. Cut-off lines represent the boundary conditions meeting the classifications of $V U$ (Vulnerable), EN (Endangered) or CR (Critically Endangered) status under IUCN Criterion A2, where population decline is higher than $30 \%(V U), 50 \%(E N)$ or $80 \%(C R)$ of initial abundance within three generations for cetaceans [2]

the cetacean populations lacking periodical census baselines, method alternative to census technique is needed to approximate population trend and status.

\section{Demography approach of trend and status assessment}

Based on survival-reproduction modeling demographic approach provides an indirect way to estimate population trend and, particularly, forecast the risk of extinction, including the probabilities (PE) and date (TE) of extinction, under assumed scenarios for threatened species/populations [7-9,26]. The PE estimate itself becomes another 


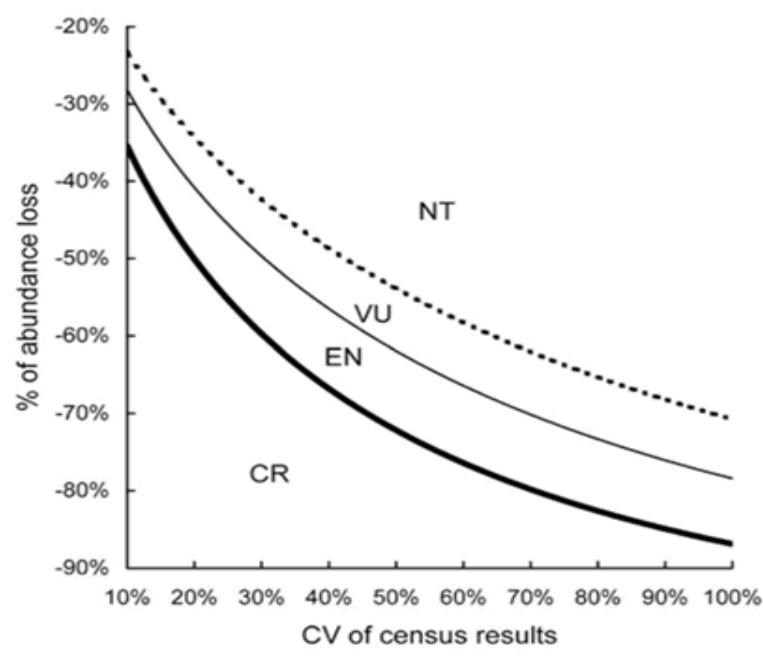

Figure 2: \% of abundance loss when abundance declines become detectable at different levels of abundance estimate CV.

quantitative assessment of population status under Criterion $\mathrm{E}$ of the IUCN Red List Categories and Criteria Version 3.1 [2].

Recent studies of trend projections show the usefulness of demographic approach in quantifying the survival risk of an endangered population. Mei et al., [9] reports that the Yangtze finless porpoise has been declining since the late 1970s but the rate of population decline has been accelerating since the early 1990 s, from lower than $2 \%$ abundance per annum before 1993 to faster than 6\% abundance per annum after 1993. Meta-analyses of data collected by systematic boat surveys in the mainstream of the Yangtze River between 1990 and 2007 [24, 27] estimate an average of $6.4 \%$ decline of abundance per annum [9]. The consistency of results from two independent studies applying different methodological approaches, demographic approach and traditional census technique, demonstrates the power of demographic analyses.

The interpretation of demographic analysis, however, should be cautious especially when applied to threatened populations that are endangered by escalating anthropogenic impacts. Most demographic models assume that current environmental conditions do not change much over time [28-30]. In reality, environmental conditions may and often do change with time, thus altering the risk of local extinction in future. Species or populations usually begin attracting conservation attention only after they are exposed to severe environmental degradation or habitat loss, or when once common animals are not seen frequently anymore. In such instances, the animals may indeed have been struggling for their long-term biological survival in the face of environmental uncertainty of increasingly deteriorating habitats [17] that are closely related to exponentially increasing economic and human population growth [31-34]. The survivorship of threatened species or populations predicted by demographic analyses should be viewed as optimistic compared to the true survivorship. This risk can be particularly critical in rapid developing countries where cetaceans inhabit waters nearby intense human activities including urbanization, industrialization and long-term coastal change (Figure 3).

To run demographic analysis two sets of quantitative baselines are needed before applying the survival-reproduction modeling: the agespecific reproductive rates, $\mathrm{m}(\mathrm{x})$, and age-specific survivorship, $l(x)$. The $m(\mathrm{x})$ can be approximately defined as follows: [35]
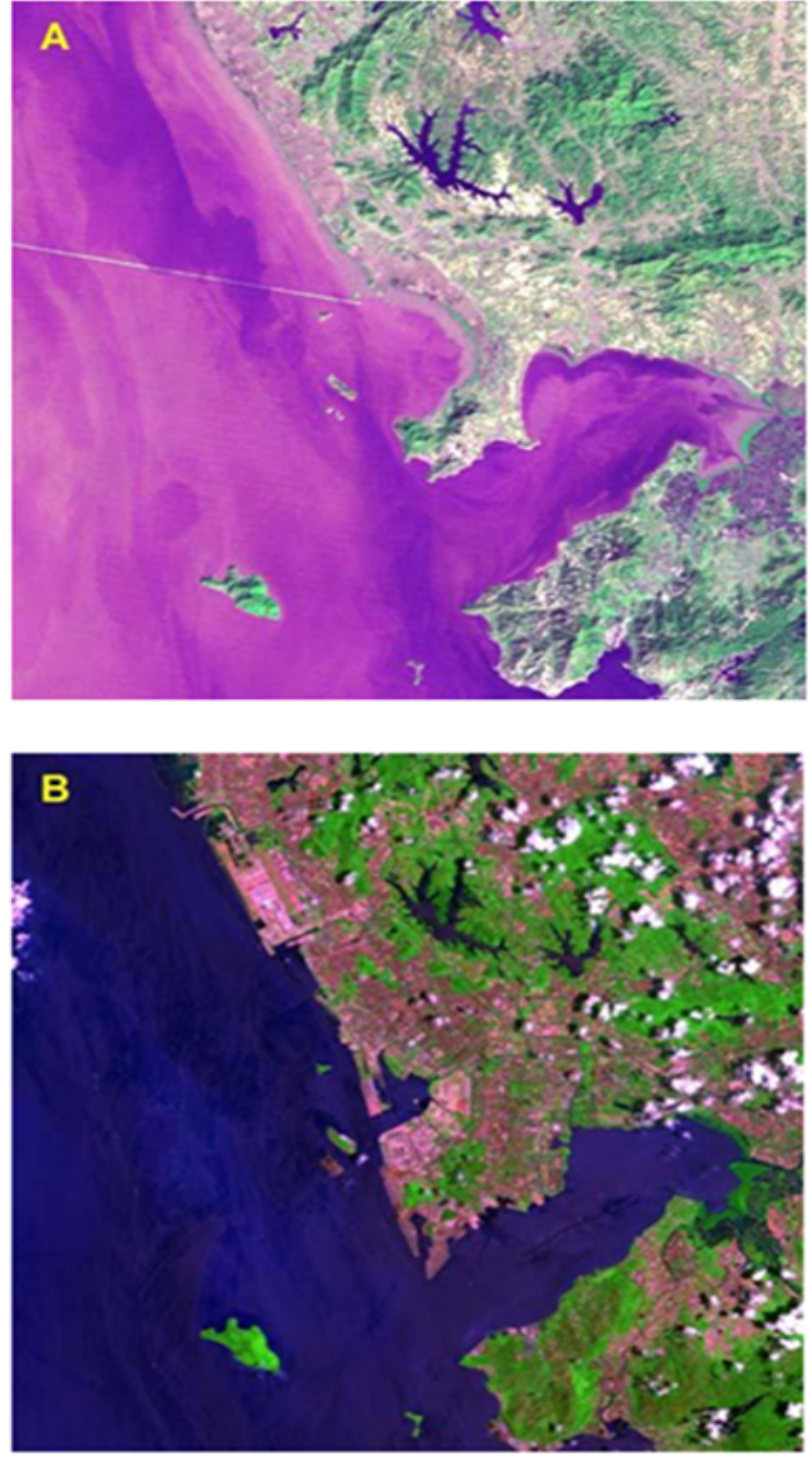

Figure 3: Long-term landscape change along Shenzhen coast, Guandong Province, China, from 1973 to 2013 , indicating significant coastal habitat loss due to land reclamation and substantial landscape change to urbanization. Band composition: RGB231 for Landsat 1 MSS (1973) and RGB753 for Landsat 8 OLI (2013).

$$
\begin{gathered}
m(\mathrm{x})=0,0 \leq x<A m(2) \\
m(\mathrm{x})=\rho / \mathrm{R} 1, A m \leq x<A x
\end{gathered}
$$

Calving) interval, and represents expected proportion of female calves (often assumed to be 0.50) $[8,9,17]$. Values or ranges of $A m$, $C I$ and $A x$ need direct feedback from life history studies through the analysis of reproductive status at various ages [8,36-38] or the longterm capture-mark-recapture (CMR) exercise by individual photo-ID histories [39-41].

The $l(x)$ can be constructed by life-table analysis or CMR exercise. In the life-table approach, life table parameters including the number of alive at age $\mathrm{x}\left(n_{x}\right)$, proportion surviving to age $\mathrm{x}\left(l_{x}\right)$ and mortality rate at age $\mathrm{x}\left(q_{x}\right)$, can be calculated using a standard method based on the age-at-death database (Table 2) $[8,9,42-44]$. For cetaceans I recommend the application of Siler's model [45] to calculated $\mathrm{lx}$ to 
build a age-specific survivorship model, $l(x)$, with quantifiable range of uncertainties $[8,9,43]$. In the Siler's model, age-specific survivorship, $l(x)$, is determined by three components:

$$
l(x)=l_{\mathrm{j}}(\mathrm{x}) \times l_{c}(\mathrm{x}) \times l_{s}(\mathrm{x})(3),
$$
factors

including an exponentially decreasing risk due to juvenile risk

$$
l_{j}(\mathrm{x})=\exp \left(-\mathrm{a}_{1} / \mathrm{b}_{1}\left(1-\exp \left(-\mathrm{b}_{1} \times \mathrm{x}\right)\right)\right)(3.1)
$$

a constant risk experienced by all age classes

$$
l_{c}(\mathrm{x})=\exp \left(a_{2} \times x\right)(3.2),
$$

and an exponentially increasing risk due to senescent risk factors,

$$
l_{s}(\mathrm{x}) \exp \left(a^{3} / b^{3}\left(1 \exp \left(b^{3} \times x\right)\right)\right)(3.3),
$$

Where $\mathrm{x}$ is the age and $\mathrm{a} 1, b_{1}, \mathrm{a} 2, \mathrm{a} 3$, and $b_{3}$ are the Siler's parameters that can be estimated through statistical process such as non-linear regression modeling.

The life-table approach to estimate population trend usually needs massive collection of age-at-death data while the construction of $l_{x}$ and following $l(x)$ is highly sensitive to the evenness of data collection. A data-collection network run by research institutes, local governments and conservation groups is needed to facilitate the collection of stranded or by caught carcasses in a systematic way.

In the CMR exercise, $l(x)$ can be constructed by

$$
l(x)=S c \times S a^{x 1}(4),
$$

where Sc and Sa are the survival rates of calf $(\mathrm{x} \leq 1)$ and non-calf animals [17]. Both Sc and Sa can be solved by photo-ID histories $[14,29,46-49]$. An iterated simulation run by re-sampling survival rates ( $S c$ and $S a$ both and independently) within their lower-upper limits may be introduced to factor in the uncertainties with quantifiable ranges.

\section{Systematic demographic analysis: an integrative perspective}

One of the difficulties in constructing population baselines for status and risk assessment for the threatened species or populations comes from the lack of representative database with sufficient resolution to estimate demographic parameters. As previously described traditional census techniques requires decade of survey efforts to construct a database to estimate population trend. The life history study and demographic analysis, on the other hand, need extensive and often long-term data accumulation from either carcass collection or photoID histories. In general case these studies may be implemented by different research teams that use different sampling and analyzing processes, which brings another difficulty in constructing quantitative baselines: insufficient connection of demographic parameters among different researches.

Here, I propose an integrative perspective, the systematic demographic analysis (SDA), for the cetacean populations lacking quantitative baselines essential for status and risk assessment (Figure 4). Implementation of systematically-designed census exercise can provide quantitative baselines in an integrative way. The implementation of transect survey, with the information of GPS and animal-sighting records at each sampling sites, does not only estimate the population abundance inside the survey area but also figures the extent of occurrence by minimum convex polygon (MCP) and core/critical distribution site (such as $50 \%$ kernel density estimate), information essential for sound protected area design [13,16,50-54]. Database from individual photo-ID histories can be used to estimate population size, apparent survival rate and, dependent on the temporal scale of database, life history parameters including $A m, R I$ and $A x$. Database of age-reproductive status records collected from stranded and by caught carcasses can be used to solve both life history parameters and age-specific survivorships or mortality rates. With the help from genetic diversity analysis the collection of carcasses can further provide information of population genetic diversity [55-58], which is an indirect

\begin{tabular}{|c|c|c|c|c|c|c|}
\hline age & male & female & male & female & male & female \\
\hline 0 & 11 & 13 & 1.000 & 1.000 & 0.224 & 0.277 \\
\hline 1 & 2 & 3 & 0.776 & 0.723 & 0.053 & 0.088 \\
\hline 2 & 3 & 3 & 0.735 & 0.660 & 0.083 & 0.097 \\
\hline 3 & 4 & 7 & 0.673 & 0.596 & 0.121 & 0.250 \\
\hline 4 & 4 & 3 & 0.592 & 0.447 & 0.138 & 0.143 \\
\hline 5 & 4 & 2 & 0.510 & 0.383 & 0.160 & 0.111 \\
\hline 6 & 5 & 4 & 0.429 & 0.340 & 0.238 & 0.250 \\
\hline 7 & 2 & 3 & 0.327 & 0.255 & 0.125 & 0.250 \\
\hline 8 & 2 & 0 & 0.286 & 0.191 & 0.143 & 0.000 \\
\hline 9 & 3 & 0 & 0.245 & 0.191 & 0.250 & 0.000 \\
\hline 10 & 4 & 0 & 0.184 & 0.191 & 0.444 & 0.000 \\
\hline 11 & 3 & 5 & 0.102 & 0.191 & 0.600 & 0.556 \\
\hline 12 & 0 & 2 & 0.041 & 0.085 & 0.000 & 0.500 \\
\hline 13 & 0 & 1 & 0.041 & 0.043 & 0.000 & 0.500 \\
\hline 14 & 0 & 0 & 0.041 & 0.021 & 0.000 & 0.000 \\
\hline 15 & 0 & 0 & 0.041 & 0.021 & 0.000 & 0.000 \\
\hline 16 & 2 & 1 & 0.041 & 0.021 & 1.000 & 1.000 \\
\hline
\end{tabular}
measurement of extinction risk of a threatened population [59-61]

The rate of decline can be solved by calculating the finite rate of increase $(\lambda)$ in deterministic perspective:

$$
\lambda=\exp (r)(5)
$$

$l_{x}=l_{x-1}-\frac{n_{x}}{N}, N=\Sigma n_{x}, l_{0}=1, q_{x}=1-\frac{l_{x+1}}{l_{x}}$

Table 2: Life table parameters based on age-at-death data, including number $\left(n_{x}\right)$, survivorship $\left(I_{x}\right)$ and mortality rate $\left(q_{x}\right)$ at age $x$, for the Yangtze finless porpoise population collected between 1993 and 2006 (modified from [9]). 


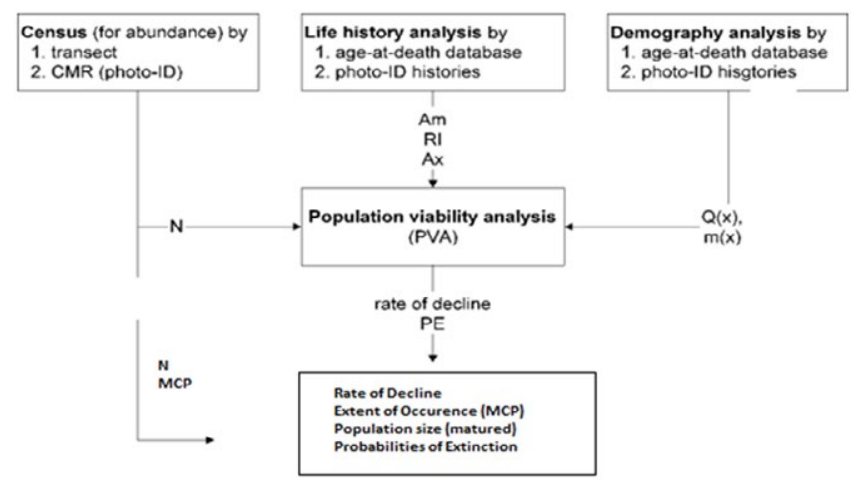

Figure 4: Schematic plot of research pipeline of systematic demographic analysis, showing four major research modules (abundance, life history, demography and PVA modules) that are traditionally implemented by independent studies.

Where $r$ is the theoretical instantaneous rate of increase. The value of $\mathrm{r}$ can be calculated by

$$
\begin{aligned}
& r=\frac{\operatorname{In}[\Sigma l(x) \times m(x)]}{T_{0}} \\
& T_{0}=\frac{\sum x \times l(x) \times m(x)}{\Sigma l(x) \times m(x)}
\end{aligned}
$$

The uncertainties from measurements of life history parameters (Am, RI and $A x$ ) and demographic rates (survival rates or mortality rates) and stochasticity from small number of population abundance, usually $<5000$, makes the task estimating population trend and predicting extinction risk more complicate. Applications of population viability analysis (PVA) such as VORTEX model [28] or the procedure described in [7] (and also see [8,9,17]) is encouraged to factor in the stochasticity and uncertainty to obtain the likely range of rate of decline and extinction risk.

Despite traditional census techniques do not have sufficient resolution to reveal recent and early sign of population decline, the importance of long-term census efforts to monitor population status, including abundance, survivorships and distribution ranges, cannot and should not be overlooked. Results from PVA exercise are highly sensitive to the characteristics of parameters input (mean, range). Though general values/ranges of life history parameters universal to species could be applied to specific population when the populationspecific values/ranges are unavailable as in [8], parameters specific to the target population $(A m, R I, A x, l(x)$ and $m(x))$ are still needed to have the most updated status information.

\section{Caution when basing conservation actions on census data}

In many developing countries the awareness and implementation of cetacean conservation often lags behind the actual degree of population decline and the extent of increasing anthropogenic impacts [17]. Thus, the 'baselines' received from field census survey may actually have been affected by anthropogenic impacts rather than the initial and unaffected status of a population. The Yangtze River dolphin, or baiji (Lipotes vexillifer), has been known continuously decline since the 1970s [24]; however, answer to the question: if baiji is still survival cannot be assured until the full-scaled census in $2006[23,24]$. The actual date when baiji became extinct definitely happened prior to 2006 but is unlikely to approach.

Pattern of spatial distribution (MCP, 50\% kernel density, the association with environmental characteristics) can be used to identify key habitat for protection. In the rapid developing countries, however, the animal distribution, especially the cetaceans inhabiting coastal or freshwater habitat, may have been affected by long-term environmental change when the census was implemented. For example, Zhao et al., [62] considers a priority area for Yangtze finless porpoise conservation at a section where porpoise sightings are high but no in situ reserve has been enacted $[9,63]$. On the basis of remotely-sensed satellite imagery, however, the spatial-demography analysis between spatio-temporal water quality change and Yangtze finless porpoise distribution indicates that it may be the extent of habitat deterioration relating to extent of eutrophication rather than different habitat preference (or quality) forming current distribution gradient of Yangtze finless porpoise in the Yangtze River (Huang SL, unpublished materials).

Direct use of animal distribution pattern from census in areas with intense human activities may mislead the strategy of habitat protection policy in cetacean conservation. The conservation of humpback dolphins off western Taiwan coast (WTC) has received high local awareness [13,63-64]. Baselines from series census indicate a very small number of population size [66] and discontinuous distribution pattern (Figure 5) [63-64]. The distribution pattern of WTC humpback dolphins, two regions of a relatively high sighting frequency separated by a stretch of coast where the animals are seen sporadically, is translated into two "hot-zones" connected by a "migratory corridor" [63-64], which guides the formulation of habitat management strategy for the humpback dolphin conservation [66]. Analysis of Landsat imagery since the 1970s, however, reveals significant coastal change, especially largescaled land reclamation in central WTC (Figure 6). Calculations on the area of land reclamation since the 1970s through Landsat imagery indicate rapid loss of coastal habitat due to land reclamation between 1980 and 2000, mostly in the central WTC, while the land reclamation reach 'ceiling' stage after 2000. The systematic survey of distribution and census of WTC humpback dolphins, on the other hand, was not implemented until 2006. The 'baselines' currently used for habitat and population management indeed came from the impacted population

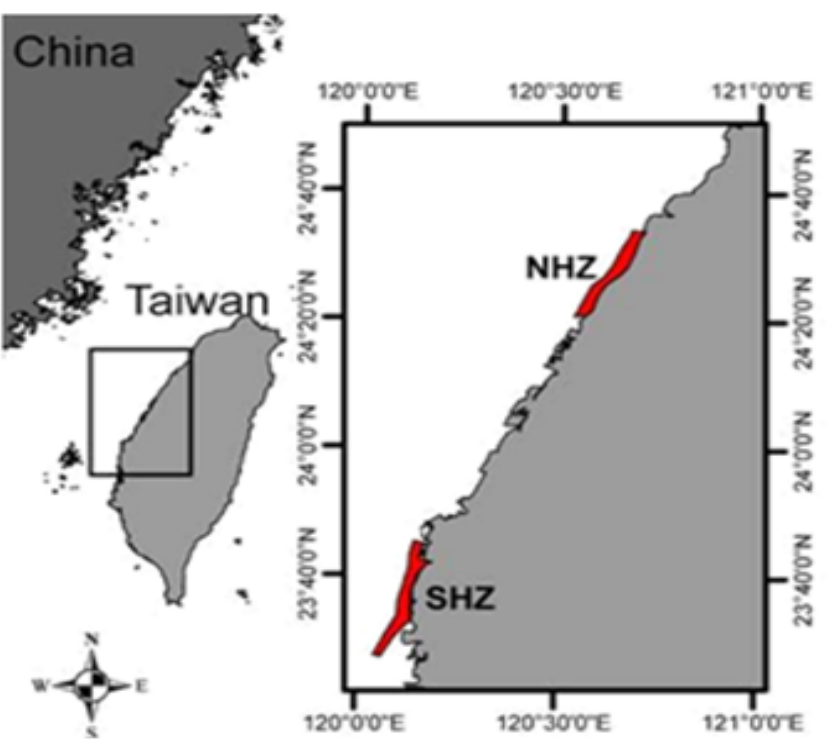

Figure 5: Major humpback dolphin (Sousa chinensis) habitat off western Taiwan coast. The two "hot-zones" of dolphin distribution identified in [64] are highlighted by "NHZ" and $\mathrm{SHZ}$. 
Citation: Huang SL (2013) Assessing Population Trend and Risk of Extinction for Cetaceans Lacking Long-Term Census Baselines. J Biodivers Endanger Species 1: 115. doi: 10.4172/2332-2543.1000115

Page 6 of 8
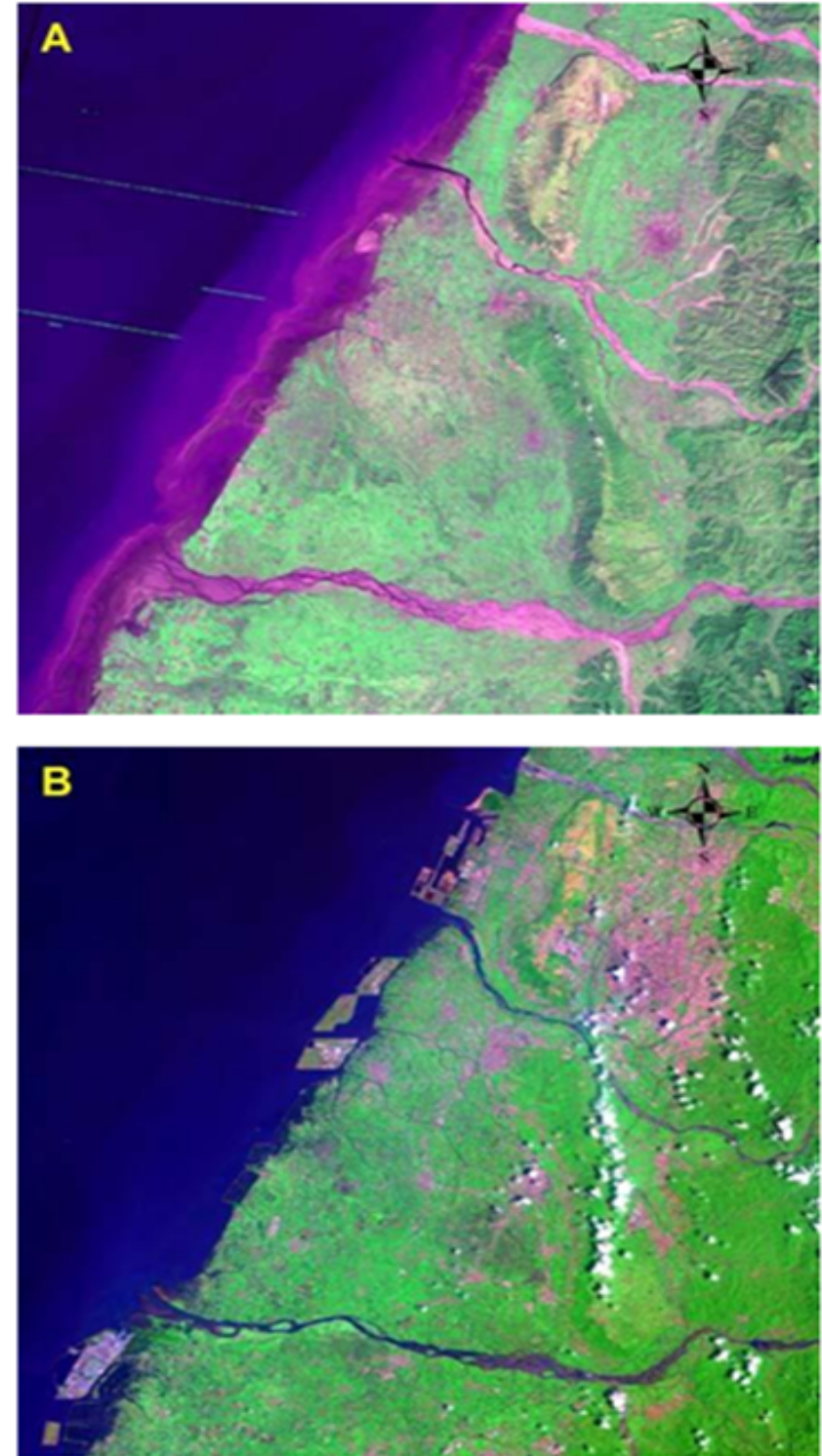

Figure 6: Long-term landscape change in central western Taiwan coast A. Landsat imagery in 1972 (Landsat 1 MSS), showing complicate coastal and estuarine systems. B. Landsate imagery taken in 2013 (Landsat 8 OLI), showing significant land use/landscape change and substantial degradation of coastal and estuarine systems in western Taiwan coast. Band composition: RGB 231 for 1972 Landsat 1 MSS and RGB 753 band composite for Landsat $8 \mathrm{OLI}$.

that has deviated from initial status. Early Landsat imagery implies a continuity of valuable habitat (Figure 6A) and therefore a continuous rather than fragmented distribution gradient of humpback dolphins should be assumed across entire WTC waters. "Hot-zone-based" habitat management programme may not effectively provide an impact-free or impact-low environment with sufficient size for the WTC humpback dolphins but, worse, restricts the WTC humpback dolphins to two fragmented habitats with 'connective corridor'. Comparable cases may comprehensively happen in many rapidly developing countries, highlighting the need to integrate histories of long-term coastal LULC (land use/landscape change) when basing habitat management strategy on census results.

\section{Conclusions}

Population trend is the baseline essential for status and risk assessment in conservation of rare and/or endangered animals. Theoretically the population trend can be estimated by the long-term census database; however, the applicability of census approach in estimating population trend is restricted by the variation $(\mathrm{CV})$ from currently-used census techniques. Power analysis indicates that it will need decades of census effort to detect the change of population size in field, which is unlikely a practical way for the cetacean populations lacking census baselines. Demographical approach, on the other hand, provides an alternative way to estimate population trend and, particularly, forecast the rate of decline and risk of extinction (PE and TE) under assumed scenarios. To apply demographic method two sets of population baselines are needed: the age-specific reproductive rates, $m(x)$, and age-specific survivorships, $l(x)$ that can be solved by analyzing database from individual photo-ID histories or age-at-death records from collected carcasses. A systematic design and application of above methods, the systematic demographic analysis, can provide quantitative baselines, including life history parameters ( $A m, R I A x)$, $m(x)$ and $l(x)$, in an integrative way for the cetacean populations lacking population baselines. Then, modeling exercise of population viability analysis factoring in parameter uncertainty and demographic stochasticity can be applied to solve the rate of decline and risk of extinction. Finally, I emphasize the need to integrate the histories of long-term land use and landscape change relating to land reclamation, urbanization and industrialization to avoid the skip of low-sighting habitat from intense anthropogenic impacts when formulating habitat management programme based on the feedbacks from census.

\section{Acknowledgement}

This work was supported by the grants from the National Science Council of Taiwan (grant NSC 101-2311-B-019-002). No competitive interest conflict is declared.

\section{References}

1. Turvey ST, Barrett LA, Yujiang H, Lei Z, Xinqiao Z, et al. (2010) Rapidly shifting baselines in Yangtze fishing communities and local memory of extinct species. Conserv Biol 24: 778-787.

2. IUCN (2001) Red List Categories and Criteria version 3.1 IUCN Species Survival Commission. IUCN, Gland, Switzerland and Cambridge, UK.

3. Chaloupka M, Osmond M, Kaufman G (1999) Estimating Seasonal Abundance Trends and Survival Probabilities of Humpback Whales in Hervey Bay (East Coast Australia). Marine Ecology Progress Series 184: 291-301.

4. Buckland ST, Breiwick JM (2002) Estimated Trends in Abundance of Eastern Pacific Gray Whales from Shore Counts (1967/68 to 1995/96). Journal of Cetacean Research and Management 4: 41-48.

5. "CRAIG" George JC, Zeh J, Suydam R, Clark C (2004) Abundance And Population Trend (1978-2001) of Western Arctic Bowhead Whales Surveyed Near Barrow, Alaska. Mar Mammal Sci 20: 755-773.

6. Zerbini AN, Waite JM, Laake JL, Wade PR (2006) Abundance, trends and distribution of baleen whales off Western Alaska and the central Aleutian Islands. Deep-Sea Research Part I 53: 1772-1790.

7. Currey RJC, Dawson SM, Slooten E (2009) An approach for regional threat assessment under IUCN Red List criteria that is robust to uncertainty: The Fiordland bottlenose dolphins are critically endangered. Biol Conserv 142 1570-1579.

8. Huang S-L, Karczmarski L, Chen J, Zhou R, Lin W, et al. (2012) Demography and population trends of the largest population of Indo-Pacific humpback dolphins. Biol Conserv 147: 234-242.

9. Mei Z, Huang S-L, Hao Y, Turvey ST, Gong W, et al. (2012) Accelerating population decline of Yangtze finless porpoise (Neophocaena asiaeorientalis asiaeorientalis). Biol Conserv 153: 192-200 
Citation: Huang SL (2013) Assessing Population Trend and Risk of Extinction for Cetaceans Lacking Long-Term Census Baselines. J Biodivers Endanger Species 1: 115. doi: 10.4172/2332-2543.1000115

Page 7 of 8

10. Zhang X, Wang D, Liu R, Wei Z, Hua Y, et al. (2003) The Yangtze River dolphin or baiji (Lipotes vexillifer): population status and conservation issues in the Yangtze River, China. Aquat Conserv 13: 51-64.

11. Braulik GT (2006) Status assessment of the Indus River dolphin, Platanista gangetica minor, March - April 2001. Biol Conserv 129: 579-590.

12. Wang D (2009) Population status, threats and conservation of the Yangtze finless porpoise. Chinese Science Bulletin 54: 3473-3484.

13. Ross PS, Dungan SZ, Hung SK, Jefferson TA, Macfarquhar C, et al. (2010) Averting The Baiji Syndrome: Conserving Habitat for Critically Endangered Dolphins in Eastern Taiwan Strait. Aquat Conserv 20: 685-694.

14. Ryan GE, Dove V, Trujillo F, Doherty Jr PF (2011) Irrawaddy dolphin demography in the Mekong River: an application of mark - resight models. Ecosphere.

15. Braulik GT, Reichert AP, Ehsan T, Khan S, Northridge SP, et al. (2012) Habitat Use by a Freshwater Dolphin in the Low-Water Season. Aquat Conserv 22 533-546.

16. Gomez-Salazar C, Trujillo F, Portocarrero-Aya M, Whitehead H (2012) Population, density estimates, and conservation of river dolphins (Inia and Sotalia) in the Amazon and Orinoco river basins. Mar Mammal Sci 28: 124-153.

17. Huang S-L, Hao Y, Mei Z, Turvey ST, Wang D (2012) Common Pattern of Population Decline for Freshwater Cetacean Species in Deteriorating Habitats. Freshwater Biol 57: 1266-1276.

18. Jefferson TA (2000) Population biology of the Indo-Pacific hump-backed dolphin in Hong Kong waters. Wildlife Monogr 144: 1-65.

19. Jefferson TA, Hung SK (2004) A Review of the Status of the Indo-Pacific Humpback Dolphin (Sousa Chinensis) in Chinese Waters. Aquatic Mammals 30: $149-158$

20. Gerrodette T (1987) A Power Analysis for Detecting Trends. Ecology 68: 1364 1372.

21. Thompson PM, Wilson B, Grellier K, Hammond PS (2000) Combining Power Analysis And Population Viability Analysis to Compare Traditional and Precautionary Approaches to Conservation of Coastal Cetaceans. Conserv Biol 14: 1253-1263.

22. Taylor BL, Martinez M, Gerrodette T, Barlow J, Hrovat YN (2007) Lessons from Monitoring Trends in Abundance of Marine Mammals. Marine Mammal Science 23: $157-175$

23. Wang K, Wang D, Zhang X, Pfluger A, Barrett L (2006) Range-wide Yangtze freshwater dolphin expedition: The last chance to see Baiji? Environ Sci Pollut Res Int 13: 418-424.

24. Turvey ST, Pitman RL, Taylor BL, Barlow J, Akamatsu T, et al. (2007) First human-caused extinction of a cetacean species? Biol Lett 3: 537-540.

25. Mei Z (2013) Study on the Population Dynamics and Endangerd Mechanism of the Yangtze Finless Porpoise (Neophocaena asiaeorientalis asiaeorientalis). Ph.D. Dissertation. University of Chinese Academy of Science, Institute of Hydrobiology, Chinese Academy of Science, Wuhan, Hubei, China.

26. Fujiwara M, Caswell H (2001) Demography of the endangered North Atlantic right whale. Nature 414: 537-541.

27. Zhang X, Liu R, Zhao Q, Zhang G, Wei Z, et al. (1993) The population of finless porpoise in the middle and lower reaches of the Yangtze River, China. Acta Theriol Sinica 13: 260-270.

28. Lacy RC (1993) VORTEX: A Computer Simulation Model for Population Viability Analysis. Wildlife Res 20: 45-65.

29. Caswell H, Fujiwara M, Brault S (1999) Declining survival probability threatens the North Atlantic right whale. Proc Natl Acad Sci U S A 96: 3308-3313.

30. Winship AJ, Trites AW (2006) Risk of Extirpation Of Steller Sea Lions in The Gulf of Alaska and Aleutian Islands: A Population Viability Analysis Based on Alternative Hypotheses for why Sea Lions Declined in Western Alaska. Mar Mammal Sci 22: 124-155.

31. Chevé M (2000) Irreversibility of Pollution Accumulation. Environmental and Resource Economics 16: 93-104

32. Bearzi G, Holcer D, di Sciara GN (2004) The Role Of Historical Dolphin Takes And Habitat Degradation In Shaping The Present Status Of Northern Adriatic Cetaceans. Aquat Conserv 14: 363-379.

33. Bearzi G, Agazzi S, Gonzalvo J, Bonizzoni S, Costa M, et al. (2010) Biomass
Removal by Dolphins And Fisheries in A Mediterranean Sea Coastal Area: Do Dolphins Have an Ecological Impact on Fisheries? Aquat Conserv 20: 549-559.

34. Piroddi C, Bearzi G, Gonzalvo J, Christensen V (2011) From common to rare: The case of the Mediterranean common dolphin. Biol Conserv 144: 2490-2498.

35. Slooten E (1991) Age, Growth and Reproduction in Hector's Dolphin. Can J Zool 69: 1689-1700.

36. Evans K, Hindell MA (2004) The age structure and growth of female sperm whales (Physeter macrocephalus) in southern Australian waters. J Zool 263 237-250.

37. Hao YJ, Chen DQ, Zhao QZ, Wang D (2007) Serum concentrations of gonadotropins and steroid hormones of Neophocaena phocaenoides asiaeorientalis in middle and lower regions of the Yangtze River. Theriogenology 67: $673-680$

38. Jefferson TA, Hung SK, Robertson KM, Archer FI (2011) Life History of the Indo-Pacific Humpback Dolphin in the Pearl River Estuary, Southern China. Mar Mammal Sci 28: 84-104.

39. Herzing DL (1997) The Life History of Free-Ranging Atlantic Spotted Dolphins (Stenella Frontalis): Age Classes, Color Phases, and Female Reproduction. Mar Mammal Sci 13: 576-595.

40. Hamilton PK, Knowlton AR, Marx MK, Kraus SD (1998) Age Structure and Longevity in North Atlantic Right Whales, Eubalaena Glacialis, and their Relation to Reproduction. Mar Ecol Prog Ser 171: 285-293.

41. de Oliveira Santos MC, Acuña LB, Rosso S (2001) Insights On Site Fidelity And Calving Intervals of the Marine Tucuxi Dolphin (Sotalia Fluviatilis) in SouthEastern Brazil. J Mar Biol Assoc Uk 81: 1049-1052.

42. Barlow J, Boveng P (1991) Modeling Age-Specific Mortality for Marine Mammal Populations. Mar Mammal Sci 7: 50-65.

43. Stolen MK, Barlow J (2003) A Model Life Table For Bottlenose Dolphins (Tursiops Truncatus) From The Indian River Lagoon System, Florida, U.S.A Mar Mammal Sci 19: 630-649.

44. Moore JE, Read AJ (2008) A Bayesian uncertainty analysis of cetacean demography and bycatch mortality using age-at-death data. Ecol Appl 18 1914-1931.

45. Siler W (1979) A Competing-Risk Model for Animal Mortality. Ecology 60: 750-757.

46. Slooten E, Dawson SM, Lad F (1992) Survival Rates of Photographically Identified Hector's Dolphins from 1984 to 1988. Mar Mammal Sci 8: 327-343.

47. Clapham PJ, Barlow J, Bessinger M, Cole T, Mattila D, (2003) Abundance and Demographic Parameters of Humpback Whales From The Gulf of Maine, and Stock Definition Relative to The Scotian Shelf. Journal of Cetacean Research and Management 5: 13-22.

48. Verborgh P, De Stephanis R, Pérez S, Jaget Y, Barbraud C, (2009) Survival Rate, Abundance, and Residency of Long-Finned Pilot Whales in The Strait of Gibraltar. Mar Mammal Sci 25: 523-536.

49. Mansur RM, Strindberg S, Smith BD (2012) Mark-Resight Abundance and Survival Estimation of Indo-Pacific Bottlenose Dolphins, Tursiops Aduncus, in The Swatch-Of-No-Ground, Bangladesh. Mar Mammal Sci 28: 561-578.

50. Flores PAC, Bazzalo M (2004) Home Ranges and Movement Patterns of the Marine Tucuxi Dolphin, Sotalia Fluviatilis, in Baía Norte, Southern Brazil. Latin American Journal of Aquatic Mammals 3: 37-52.

51. Rayment W, Dawson S, Slooten E, Bräger S, Fresne SD, (2009) Kerne Density Estimates of Alongshore Home Range of Hector's Dolphins at Banks Peninsula, New Zealand. Mar Mammal Sci 25: 537-556.

52. Chen B-Y, Zheng D-M, Ju J-F, Xu X-R, Zhou K-Y, et al. (2011) Range Patterns of Resident Indo-Pacific Humpback Dolphins (Sousa Chinensis, Osbeck 1765) in Xiamen, China: Implications for Conservation And Management. Zool Stud 50: 751-762

53. Silva MA, Prieto R, Magalhães S, Seabra MI, Machete M, (2012) Incorporating Information on Bottlenose Dolphin Distribution into Marine Protected Area Design. Aquat Conserv 22: 122-133.

54. Keith M, Atkins S, Johnson AE, Karcsmarski L (2013) Area Utilization Patterns Of Humpback Dolphins (Sousa Plumbea) In Richards Bay, Kwazulu-Natal, South Africa. J Ethol 31: 261-274. 
Citation: Huang SL (2013) Assessing Population Trend and Risk of Extinction for Cetaceans Lacking Long-Term Census Baselines. J Biodivers Endanger Species 1: 115. doi: 10.4172/2332-2543.1000115

Page 8 of 8

55. Yang G, Ren W, Zhou K, Liu S, Ji G, (2002) Population Genetic Structure of Finless Porpoises, Neophocoena Phocaenoides, in Chinese Waters, Inferred from Mitochondrial Control Region Sequences. Mar Mammal Sci 18: 336-347.

56. Xia J, Zheng J, Wang D (2005) Ex Situ Conservation Status of An Endangered Yangtze Finless Porpoise Population (Neophocaena Phocaenoides Asiaeorientalis) As Measured From Microsatellites and Mtdna Diversity. ICES J Mar Sci 62: 1711-1716.

57. Zheng JS, Xia JH, He SP, Wang D (2005) Population genetic structure of the Yangtze finless porpoise (Neophocaena phocaenoides asiaeorientalis): implications for management and conservation. Biochem Genet 43: 307-320.

58. Li X, Liu Y, Tzika AC, Zhu Q, Van Doninck K, et al. (2011) Analysis of Globa and Local Population Stratification of Finless Porpoises Neophocaena Phocaenoides in Chinese Waters. Marine Biology 158: 1791-1804.

59. Curtis C, Stewart BS, Karl SA (2011) Genetically effective population sizes of Antarctic seals estimated from nuclear genes. Conserv Genet 12: 1435-1446.

60. Tucker KP, Hunter ME, Bonde RK, Austin JD, Clark AM, (2012) Low Genetic Diversity and Minimal Population Substructure in the Endangered Florida Manatee: Implications for Conservation. J Mammal 93: 1504-1511.

61. Ansmann IC, Lanyon JM, Seddon JM, Parra GJ (2013) Monitoring dolphins in an urban marine system: total and effective population size estimates of IndoPacific bottlenose dolphins in Moreton Bay, Australia. PLoS One 8: e65239.

62. Zhao X, Wang D, Turvey ST, Taylor B, Akamatsu T (2013) Distribution Patterns of Yangtze Finless Porpoises in The Yangtze River: Implications for Reserve Management. Animal Conservation 16: 509-518.

63. Chou L-S, Lee J-D (2010) Habitat Hotspot of Humpback Dolphin, Sousa Chinensis, and Master Planning for Conservation Management (in Chinese) Forestry Bureau, Council of Agriculture, Executive Yuan, Taiwan.

64. Chou L-S, Lee J-D, Kao C-C, Chuang C-T, Chen C-F, et al. (2011) Population Ecology, Critical Habitat and Master Planning for Marine Mammal Protected Area of Indo-Pacific Humpback Dolphin, Sousa chinensis. Forestry Bureau, Council of Agriculture, Executive Yuan, Taipei, Taiwan.

65. Population Ecology, Critical Habitat and Master Planning for Marine Mammal Protected Area of Indo-Pacific Humpback Dolphin, Sousa chinensis. Ecology and Evolutionary Biology Institute, National Taiwan University.

66. Wang JY, Yang SC, Hung SK, Jefferson TA (2007) Distribution, Abundance And Conservation Status of The Eastern Taiwan Strait Population of Indo-Pacific Humpback Dolphins, Sousa Chinensis. Mammalia 71: 157-165. 